Jurnal Indonesia Sosial Teknologi: p-ISSN: 2723 - 6609

e-ISSN : 2745-5254

Vol. 2, No. 10 Oktober 2021

\title{
KAJIAN TEKNIS PENGELOLAAN AIR ASAM TAMBANG, PT SAROLANGUN BARA PRIMA, KABUPATEN SAROLANGUN, PROVINSI JAMBI
}

\author{
Niza Desiana ${ }^{1}$, Mustapa effendi Nasution ${ }^{2}$, Ngatijo ${ }^{3}$, Muhammad Ikrar Lagowa ${ }^{4}$, \\ Wahyudi Zahar ${ }^{5}$ \\ Prodi Teknik Pertambangan, Jurusan Teknik Kebumian, Fakultas Sains dan Teknologi \\ Universitas Jambi ${ }^{1,2,3,4,5}$ \\ Email: nizadesyaana@gmail.com ${ }^{1}$
}

\begin{abstract}
Abstrak
Air asam tambang terbentuk karena adanya mineral FeS (pyrite) yang teroksidasi, air asam ini berasal dari tambang atau batuan yang mengandung mineral sulfida tertentu yang terpapar dan dalam keadaan teroksidasi. Adapun sumber dari air asam tambang pada PT Sarolangun Bara Prima ini berasal dari sistem penambangan terbuka yang digunakan, khususnya pada pit penambangan yang terdapat genangan air yang berasal dari air tanah bekas lubang bor. Adapun PH rata-rata air asam tambang sebelum dilakukan treatment adalah 5 dan apabila diberi treatment $\mathrm{pH}$ rata-ratanya adalah 6.5. Dalam pengelolaan air asam tambang di PT Sarolangun Bara Prima ini diawali dengan pemindahan air asam tambang menuju sump selanjutnya dialirkan settling pond, untuk treatment menetralkan $\mathrm{pH}$ air tidak rutin dilaksanakan, air asam ini sering dialirkan langsung kesungai tanpa diberikan treatment khusus, oleh sebab itu diperlukan pengelolaan air asam tambang secara rutin dan lebih efektif agar mencegah timbulnya pencemaran lingkungan.
\end{abstract}

Kata kunci: Air asam tambang; $\mathrm{pH}$; treatment.

\section{Abstract}

Acid mine water is formed due to the presence of oxidized FeS (pyrite) minerals, this acid water comes from mines or rocks containing certain sulfide minerals that are exposed and in an oxidized state. The source of acid mine drainage at PT Sarolangun Bara Prima comes from the open-pit mining system used, especially in mining pits where there are puddles of water originating from groundwater from drill holes. The average $\mathrm{pH}$ of acid mine water before treatment is 5 and when given treatment the average $\mathrm{pH}$ is 6.5. In the management of acid mine drainage at PT Sarolangun Bara Prima, it begins with the transfer of acid mine water to the sump, then it flows into a settling pond, for treatment to neutralize the $\mathrm{pH}$ of the water is not routinely carried out, this acid water is often flowed directly into the river without being given special treatment, therefore management is needed. acid mine drainage regularly and more effectively to prevent environmental pollution.

Keywords: Acid mine water; $p H$; treatment. 


\section{Pendahuluan}

Kegiatan penambangan batubara ini memiliki dampak bagi makhluk hidup dan lingkungan sekitarnya. Baik yang bersifat positif atau yang negatif. Secara umum dampak positifnya adalah terbukanya lapangan kerja dan pemanfaatan sumber daya alam. Sedangkan dampak negatifnya adalah terganggunya lingkungan disekitar area penambangan yang mana terdapat air limbah yang dihasilkan dari kegiatan tersebut (Uyu Wahyudin, 2020).

PT Sarolangun Bara Prima merupakan salah satu perusahaan yang bergerak dibidang penambangan batubara yang berlokasi di Kabupaten Sarolangun Provinsi Jambi. Perusahaan tambang ini membagi penambangan dengan 5 front atau wilayah penambangan, yakni Pit 1, Pit 2, Pit 3, Pit 4 dan Pit 5 dengan metode tambang terbuka. Salah satu permasalahan yang terjadi pada saat penambangan batubara adalah masalah air asam tambang, yaitu air hujan atau air tanah yang tercampur dengan batuan yang mengandung sulfida tertentu yang ada di dalam batubara, sehingga air tersebut bersifat sangat asam dan biasanya mengandung zat besi serta mangan dengan konsentrasi yang tinggi (Idaman, 2014).

Adanya permasalahan yang dihadapi oleh PT Sarolangun Bara prima yaitu masalah pengelolaan air asam tambang yang kurang diperhatikan. Air asam tambang ini akan mengikis tanah dan batuan yang berakibat pada larutnya berbagai logam seperti besi (Fe), kadmium ( $\mathrm{Cd})$, mangan ( $\mathrm{Mn})$, dan seng ( $\mathrm{Zn})$. Dengan demikian, selain ditandai oleh $\mathrm{pH}$ yang rendah, air asam tambang juga akan mengandung logam-logam dengan konsentrasi tinggi, sehingga dapat berakibat buruk pada kesehatan lingkungan maupun manusia. Upaya pengelolaan air asam tambang sangat penting dilakukan untuk meminimalkan risiko negatif terhadap kesehatan manusia dan lingkungan. Pencegahan kerusakan lingkungan ini dilakukan sesuai dengan Peraturan Menteri Lingkungan Hidup No 113 Tahun 2003 mengenai standar baku mutu lingkungan air diarea penambangan yang harus dikelola dan dikontrol sebelum dilepaskan diperairan bebas. Oleh karena itu, pengelolaan air asam tambang yang optimal selalu menjadi salah satu tantangan utama yang dihadapi oleh industri pertambangan. Untuk itu kegiatan pengendalian terhadap air asam tambang penting dilakukan selama kegiatan penambangan berlangsung dan setelah kegiatan penambangan berakhir (Indra Wahyudin, Widodo, \& Nurwaskito, 2018).

\section{Metode Penelitian}

Penelitian ini dilaksanakan di PT Sarolangun Bara Prima pit 1 yang berlokasi di Desa Mandiangin Pasar, Kecamatan Mandiangin, Kabupaten Sarolangun, Provinsi Jambi .Penelitian ini dilakukan selama satu bulan yaitu 1 Agustus 2019 sampai 31 Agustus 2019. Metodologi yang digunakan dalam kegiatan ini adalah kajian literatur serta analisis data primer. Dalam metodologi ini langkah-langkah yang diambil adalah melakukan kajian literatur tentang air asam tambang serta metode pengolahan air asam tambang (Hermawan, 2011). Tahap pengolahan data meliputi pengukuran $\mathrm{pH}$ dilakukan langsung di lapangan di area settlind pond (UTAMA \& KUTAI, 2017). Selanjutnya di catat data 
$\mathrm{pH}$, lalu dibandingkan dengan $\mathrm{pH}$ sebelum dan sesudah diberikan treatment. Tahapan dalam penelitian ini meliputi:

1. Studi Literatur

2. Kegiatan lapangan dan pengambilan data

3. Pengolahan dan analisis data

4. Hasil penelitian

\section{Hasil dan Pembahasan}

\section{Pembentukan air asam tambang}

Air asam tambang terbentuk karena adanya mineral FeS (pyrite) yang teroksidasi. Air asam tambang (acid mine drainage, $A M D$ ) atau air asam batuan, yang secara keseluruhan disebut air asam (acid drainage, $A D$ ), adalah air yang berasal dari tambang atau batuan yang mengandung mineral sulfida tertentu yang terpapar dan dalam keadaan teroksidasi (Said, 2014). Beberapa sulfida logam yang sering dijumpai pada wilayah pertambangan antara lain $\mathrm{FeS}$ (pyrite), $\mathrm{FeS}_{2}$ (marcasite), FexSx (pyrrhotite), $\mathrm{PbS}$ (galena), $\mathrm{Cu}_{2} \mathrm{~S}$ (chalco-cite), $\mathrm{CuS}$ (covellite), $\mathrm{CuFeS}_{2}$ (chalcopyrite), $\mathrm{MoS}_{2}$ (molybdenite) (Anonim, 2006).

\section{Hasil Pengukuran pH Air Asam Tambang}

Pengukuran $\mathrm{pH}$ sebelum dan sesudah diberikan treatment bertujuan untuk mengetahui nilai $\mathrm{pH}$ sebelum dan sesudah diberikan treatment Peraturan Menteri Lingkungan Hidup No 113 Tahun 2003 mengenai standar baku mutu lingkungan air diarea penambangan yang harus dikelola dan dikontrol sebelum dilepaskan diperairan bebas (Womal, 2019).

Tabel 1. Data pengukuran $\mathrm{pH}$

\begin{tabular}{llll}
\hline No & Tanggal & $\begin{array}{l}\mathrm{pH} \text { air (Sebelum di } \\
\text { treatment) }\end{array}$ & $\begin{array}{l}\mathrm{pH} \text { air (Setelah di } \\
\text { treatment) }\end{array}$ \\
\hline 1 & 1 Agustus 2019 & 4 & 6.5 \\
\hline 2 & 2 Agustus 2019 & 5 & 6 \\
\hline 3 & 3 Agustus 2019 & 5 & 6 \\
\hline 4 & 4 Agustus 2019 & 5 & 7 \\
\hline 5 & 5 Agustus 2019 & 4 & 6.5 \\
\hline 6 & 6 Agustus 2019 & 5 & 7 \\
\hline 7 & 7 Agustus 2019 & 4 & 6.5 \\
\hline 8 & 8 Agustus 2019 & 4 & 6 \\
\hline 9 & 9 Agustus 2019 & 5 & 6.5 \\
\hline 10 & 10 Agustus 2019 & 5 & 7 \\
\hline 11 & 11 Agustus 2019 & 4 & 6.5 \\
\hline 12 & 12 Agustus 2019 & 5 & 6 \\
\hline 13 & 13 Agustus 2019 & 5 & 6.5 \\
\hline 14 & 14 Agustus 2019 & 4 & 6 \\
\hline
\end{tabular}




\begin{tabular}{llll}
\hline 15 & 15 Agustus 2019 & 4 & 6.5 \\
\hline 16 & 16 Agustus 2019 & 4 & 7 \\
\hline 17 & 17 Agustus 2019 & 5 & 6.5 \\
\hline 18 & 18 Agustus 2019 & 4 & 7 \\
\hline 19 & 19 Agustus 2019 & 5 & 6.5 \\
\hline 20 & 20 Agustus 2019 & 5 & 6 \\
\hline 21 & 21 Agustus 2019 & 5 & 6 \\
\hline 22 & 22 Agustus 2019 & 4 & 6.5 \\
\hline 23 & 23 Agustus 2019 & 4 & 6.5 \\
\hline 24 & 24 Agustus 2019 & 4 & 7 \\
\hline 25 & 25 Agustus 2019 & 5 & 6.5 \\
\hline 26 & 26 Agustus 2019 & 5 & 6 \\
\hline 27 & 27 Agustus 2019 & 4 & 6.5 \\
\hline 28 & 28 Agustus 2019 & 4 & 6 \\
\hline 29 & 29 Agustus 2019 & 5 & 6 \\
\hline 30 & 30 Agustus 2019 & 5 & 6.5 \\
\hline 31 & 31 Agustus 2019 & 5 & 6 \\
\hline
\end{tabular}

\section{Tahapan pengelolaan air asam tambang}

Air yang dipompa dari sump menuju ke settling pond telebih dahulu dipompa kedalam settling pond 1 . Air yang telah ada pada kolam pertama akan mengalir ke settling pond 2 dengan melewati paritan yang menghubungkan kedua kolam ini (Hidayat, 2017). Dan selanjutnya akan menerus hingga air masuk kedalam kolam settling pond 3. Adapun setiap saluran pada settling pond dibuat zig-zag yang bertujuan untuk memaksimalkan pengendapan air tersebut.

Pada gambar dibawah merupakan bentukan dari settling pond yang terdapat di PT. Sarolangun Bara Prima terdiri atas 3 zona yaitu:

a. Zona pengendapan

Zona ini berfungsi sebagai tempat masuknya air yang bercampur dengan padatan dalam bentuk lumpur ke dalam kolam pengendapan. Zona ini merupakan tempat material padatan yang bercampur bersama air akan mengalami sedimentasi.

b. Zona penetralan

Zona ini merupakan tempat air asam tersebut akan dilakukn treatment untuk menetralkan $\mathrm{pH}$

c. Zona acuan $\mathrm{pH}$

Zona ini merupakan tempat keluaran air dan sebelum air keluar dilakukan pengecekan $\mathrm{pH}$ terlebih dahulu. 


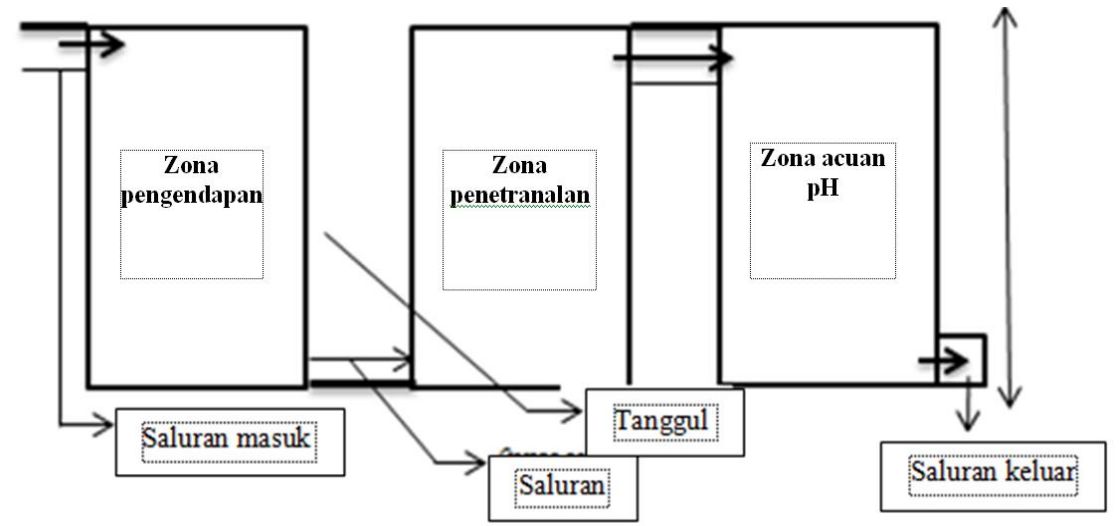

\section{Gambar 1. Dimensi Settling pond}

\section{Dampak air asam tambang}

Kegiatan pengelolaan air asam tambang, serta mengukur $\mathrm{pH}$ air asam tambang tersebut adalah untuk mengetahui apakah telah mencapai pada baku mutu atau tidak, berfungsi untuk meminimalisir dampak serius baik bagi lingkungan maupun bagi alatalat berat pada front penambangan karena dapat mempercepat laju korosi, adapun dampak negatif bagi lingkungan adalah akan mencemari lingkungan seperti merusak ekosistem biota maupun abiota pada sungai, dan apabila terkontaminasi dengan manusia dapat menyebabkan penyakit kulit, bahkan biasa melepuh, seperti penyakit minamata, oleh sebab itu pentingnya dalam pengelolaan air asam tambang (Tandiarrang, 2016).

\section{Kesimpulan}

Kesimpulan dari penelitian ini adalah : 1. Air Asam Tambang adalah salah satu masalah utama yang mempengaruhi operasi pertambangan batu bara. Air asam tambang biasanya ditandai dengan $\mathrm{pH}$ rendah, serta konsentrasi logam (Fe, Mn) dan konsentrasi sulfat yang tinggi. Namun, tidak semua air asam tambang memiliki $\mathrm{pH}$ rendah, kadang pH nya mendekati netral tetapi mengandung konsentrasi padatan tersuspensi tinggi. Jika pembentukan air asam tambang tidak dapat dicegah, maka diperlukan strategi minimisasi dan/atau pengolahan air asam tambang. 2. Upaya dalam pengelolaan air asam tambang yaitu dengan melakukan tahapan-tahapan peneglolaan air asam tambang yang tepat yaitu dengan cara memompa air dari dalam pit menuju sump, selanjutnya akan dipompakan kembali ke kolam settling pond dengan adanya proses treatment sepertian pemberian tawas untuk menjernihkan air dan pemberian kapur kalsium karbonat untuk menaikkan $\mathrm{pH}$ air. 3. Adapun $\mathrm{pH}$ air rata-rata pada PT Sarolangun Bara Prima sebelum dilakukan treatment adalah 5, sedangkan $\mathrm{pH}$ air setelah dilakukan treatment adalah 6,5. Permasalahan yang ditimbulkan akibat adanya kegiatan penambangan yang dilakukan oleh PT Sarolangun Bara Prima salah satunya adalah tidak dilakukannya pengelolaan secara rutin dari air asam tambang tersebut, dan tidak adanya lapisan kedap air pada lantai dan dinding settling pond, dari kedua permasalahan tersebut dapat merusak lingkungan abiota dan biota. 


\section{Bibliografi}

Anonim. (2006). Statistik Batubara Indonesia. Dikompilasi oleh Tim Kajian Batubara Nasional Kelompok Kajian Kebijakan Mineral dan Batubara.

Hermawan, Bandi. (2011). Peningkatan kualitas lahan bekas tambang melalui revegetasi dan kesesuaiannya sebagai lahan pertanian tanaman pangan.

Hidayat, Luthfi. (2017). PENGELOLAAN LINGKUNGAN AREAL TAMBANG BATUBARA:(Studi Kasus Pengelolaan Air Asam Tambang (Acid Mining Drainage) di PT. Bhumi Rantau Energi Kabupaten Tapin Kalimantan Selatan). Adhum: Jurnal Penelitian Dan Pengembangan Ilmu Administrasi Dan Humaniora, 7(1), 44-52.

Idaman, Nusa. (2014). Pengelolaan Lingkungan Areal Tambang Batubara PT. Bhumi Rantau Energi. Jurnal Pusat Teknologi Lingkungan, VII(2).

Said, Nusa Idaman. (2014). Teknologi Pengolahan Air Asam Tambang Batubara "Alternatif Pemilihan Teknologi." Jurnal Air Indonesia, 7(2).

Tandiarrang, Jenita. (2016). Studi Perbandingan Penggunaan Tawas (Al2 (SO4) 3) Dan Kapur Padam (Ca (Oh) 2) Pada Pengolahan Air Asam Tambang Di Pt Kaltim Diamond Coal Kecamatan Loa Kulu Kabupaten Kutai Kartanegara Kalimantan Timur. Jurnal Teknologi Mineral FT UNMUL, 4(1).

UTAMA, J. O. B. SITE, \& KUTAI, L. O. A. GAGAK KABUPATEN. (2017). Perbandingan penggunaan poly aluminium chloride (pac) dengan aluminium sulfat terhadap penurunan total suspended solid (tss) pada settling pond di pt. Multi harapan. Jurnal Teknologi Mineral FT UNMUL, 5(1), 43-50.

Wahyudin, Indra, Widodo, Sri, \& Nurwaskito, Arif. (2018). Analisis penanganan air asam tambang batubara. Jurnal Geomine, 6(2).

Wahyudin, Uyu. (2020). Analisis Dampak Keberadaan Perusahaan Tambang Batu Bara Terhadap Kondisi Sosial Ekonomi Masyarakat. Jurnal Ilmiah ATSAR Kuningan, $1(1), 35-45$.

Womal, Agus Margana. (2019). Studi Penanganan Air Asam Tambang Dengan Metode Aktif (Active Treatment) Pada PT. Bukit Asam Tbk (Studi Kasus KPL Saluran ALP IUP Tambang Air Laya). ReTII, 70-77. 